\title{
Manipulation under anaesthesia with local intracapsular steroid injection in treatment of frozen shoulder
}

\author{
Misra R.K. ${ }^{1}$, Batra A. ${ }^{2}$, Khajja H. ${ }^{3}$, Raja K. ${ }^{4}$ \\ ${ }^{1}$ Dr. Rakesh Kumar Misra, Associate Professor, ${ }^{2}$ Dr. Ashish Batra, Assistant Professor, ${ }^{3}$ Dr. Hemant Khajja, Senior \\ Resident, ${ }^{4}$ Dr. Kunal Raja, Senior Resident, all authors are affiliated with Department of Orthopaedics, Ananta Institute \\ of Medical Sciences, Rajsamand, Rajasthan, India.
}

Corresponding Author: Dr. Rakesh Kumar Misra, Associate Professor, Department of Orthopaedics, Ananta Institute of Medical Sciences, Rajsamand, Rajasthan. India. Email: docpages11@gmail.com

\begin{abstract}
Aims and Objective: Adhesive capsulitis of shoulder (frozen shoulder) is a condition characterized by pain, stiffness and restriction of movement of shoulder joint. The present study was carried out to assess the role of manipulation under anaesthesia along with intracapsular steroid injection in treatment of frozen shoulder. Material and Methods: The present study is a prospective study carried out in the department of Orthopedics, Ananta Institute of Medical Sciences, Rajsamand, Rajasthan during the period of 6 months from October 2018 to March 2019. 30 patients of unilateral idiopathic adhesive capsulitis (Frozen shoulder) who were symptomatic and not responding to physiotherapy were included in the study. All the patients underwent manipulation under anaesthesia and then intracapsular steroid injection was given via posterior approach. Patients were followed up regularly and reassessment using VAS (Visual analogue scale) scale and PROM (Passive Range of Motion) was done at 3 months after the procedure. Results: Out of 30 patients included in the study, $18(60 \%)$ were female and $12(40 \%)$ were male. The age of the patients ranges from 20 years to 70 years with the mean age of 46.81 years. Non dominating hand was involved in 23 cases (76.66\%). VAS score and degree of PROM were measured before and 3 months after the treatment. Conclusion: In present study, VAS score as well as PROM were significantly improved 3 months after the treatment of frozen shoulder with manipulation under anaesthesia along with intracapsular steroid injection. So, this treatment modality can be used as a safe and effective method to reduce pain and stiffness in frozen shoulder.
\end{abstract}

Keywords: Shoulder joint, Capsulitis, Intraarticular, Abduction, Physiotherapy

\section{Introduction}

Adhesive capsulitis of the shoulder (Frozen shoulder) is a condition characterized by pain and global restriction of the movement with loss of external rotation [1]. Clinically, the disease is divided into three consecutive stages: 1. Painful phase, in which there is inflammation of shoulder joint and pain in movement but no strict restriction in range of motion; 2. Stiffness phase, in which the pain is less pronounced but limitation of range of motion in all planes and 3. Recovery phase, in which there is gradual return of range of motion.

The whole disease course may lasts up to 1 to 3 years $[2,3]$. Women of age 40 to 60 years are more commonly involved. The non-dominant arm is more frequently involved. It is more common in persons with sedentary

Manuscript Received: $10^{\text {th }}$ May 2019

Reviewed: $20^{\text {th }}$ May 2019

Author Corrected: $28^{\text {th }}$ May 2019

Accepted for Publication: $1^{\text {st }}$ June 2019 lifestyle than in persons who are physically active [4,5]. The patients of frozen shoulder usually present with progressive pain of the shoulder for days to months followed by restrictions in the range of motion of the shoulder. Usually the range of motion decreases in following order: external rotation, abduction, internal rotation and forward flexion $[6,7]$.

The pathophysiology of frozen shoulder is believed to be started with inflammation of joint capsule and synovial fluid followed by reactive fibrosis and adhesions of the synovial lining of the joint $[6,8]$.

The diagnosis of frozen shoulder is made on the basis of medical history, clinical and radiological examination and exclusion of other shoulder pathology. There is no fixed regimen for the management of frozen shoulder. Various treatment modalities include conservative 
treatment with physiotherapy, exercises, NSAIDs and opioid drugs, intra-articular steroids and hyaluronic acid injection, suprascapular nerve block and manipulation under anaesthesia (MUA), open arthroscopic release with or without MUA. Many studies have been done in the past on the treatment of frozen shoulder by MUA and all have suggested a very good result with the treatment [9-13]. The present study was carried out to assess the results obtained by treatment of frozen shoulder by MUA with intracapsular steroid injection.

\section{Material and Methods}

Setting: The present study is a prospective study carried out in the department of Orthopedics, Ananta Institute of Medical Sciences, Rajsamand, Rajasthan during the period of 6 months from October 2018 to March 2019.

Type of study: Qualitative

Study population: 30 patients of unilateral idiopathic adhesive capsulitis (Frozen shoulder) who were symptomatic and not responding to physiotherapy were included in the study.

Detailed clinical history was taken and proper general examination was done in all the cases.

$\mathrm{X}$ rays in AP plane, in internal rotation and in axillary plane were also taken to exclude any other pathology of the shoulder. Ultrasound and MRI were also done in all the cases.

\section{The inclusion criteria were:}

- Age $>18$ years and $<70$ years

- Painful restriction of the passive range of motion (PROM) in the glenohumoral joint of $\geq 30^{\circ}$ in external rotation and at least a second plane of movement (forward flexion, abduction or internal rotation) with $\geq 30^{\circ}$ restriction (when compared to the contra-lateral unaffected side)

- Patients not responded to conventional physiotherapy.

The exclusion criteria were:

- Onset of symptoms $\geq 1$ year ago

- Bilateral disease

- Tumor, osteoarthritis, rheumatoid arthritis or any other pathology of the shoulder joint
Original Research Article

- History of injury or previous surgery of the shoulder

- Evidence of complete rotator cuff tear on physical examination, ultrasound or MRI

- Neurological disorder of upper limb

- Bleeding disorders or use of anticoagulant medication

- Contraindication/ allergy to corticosteroid injection

- Inability to give informed consent

Procedure: All the patients underwent manipulation under anaesthesia and then intracapsular steroid injection was given via posterior approach. Patients were followed up regularly and reassessment was done at 3 months after the procedure.

Scoring system: Visual analogue scale (VAS) was used to grade pain in present study, where ' 0 ' indicates no pain and ' 10 ' indicates worst pain possible. (14)

VAS and shoulder PROM (forward flexion, abduction, external rotation and internal rotation) were used in the present study to assess the outcome.Both the parameters were measured at start of the treatment and 3 months after the treatment.

Ethical clearance was taken from institutional ethical committee. Informed written consent was taken from all the cases involved in the study.

Statistical Analysis: Data analysis was done using statistical software SPSS version 19.0

Technique: General anaesthesia was administered to the patients with endotracheal intubation. The steps of MUA started with gradual forward elevation of arm in the sagittal plane to the maximum possible extent with fixed scapula.

Then passive external rotation was performed in $0^{\circ}$ abduction, followed by external rotation in $90^{\circ}$ of abduction.

Finally, internal rotation in $90^{\circ}$ of abduction and crossbody adduction were performed. A full range of motion was achieved in all the cases.

The shoulder joint was then injected with a solution containing $2 \mathrm{ml}$ of $80 \mathrm{mg}$ of methyl-prednisolone and $2 \mathrm{ml}$ of $2 \%$ xylocaine via posterior approach.

\section{Results}

30 patients of unilateral idiopathic adhesive capsulitis (Frozen shoulder) who were symptomatic and not responding to the conventional therapy were included in the study. The study was carried out during the period of 6 months from October 2018 to March 2019. 
Out of 30 patients, $18(60 \%)$ were female and $12(40 \%)$ were male.The age of the patients ranges from 20 years to 70 years with the mean age of 46.81 years. Non dominating hand was involved in 23 cases (76.66\%). VAS (visual analogue scale) score and degree of PROM (passive range of motion) were measured before and 3 months after the treatment. The results are depicted in table 1.

Table-1: Comparison of clinical parameters before and after treatment.

\begin{tabular}{|l|c|c|c|c|}
\hline S. No. & Clinical parameter & $\begin{array}{c}\text { Before treatment } \\
(\text { Mean } \pm \text { SD) }\end{array}$ & $\begin{array}{c}\text { 3 months after treatment } \\
(\text { Mean } \pm \text { SD) }\end{array}$ & p-value \\
\hline 1. & VAS score & $8.1 \pm 1.2$ & $4.3 \pm 1.0$ & $<0.0001$ \\
\hline 2. & PROM $\left({ }^{\circ}\right)$ & & & \\
\hline & Flexion & $119.5 \pm 15.3$ & $160.2 \pm 17.1$ & $<0.0001$ \\
\hline & Abduction & $107.7 \pm 11.8$ & $159.5 \pm 13.2$ & $<0.0001$ \\
\hline & External rotation & $33.8 \pm 9.0$ & $77.2 \pm 12.1$ & $<0.0001$ \\
\hline & Internal Rotation & $22.1 \pm 7.7$ & $43.6 \pm 9.9$ & $<0.0001$ \\
\hline
\end{tabular}

In present study, the VAS score before starting the treatment was $8.1 \pm 1.2$ which was reduced to $4.3 \pm 1.0$ when measured 3 months after the treatment. Also, the degree of range of motion was improved very much in all the movement viz flexion, abduction, external rotation and internal rotation (table 1). The results suggested that combined therapy using MUA along with intra articular steroid injection is an effective method to treat frozen shoulder.

\section{Discussion}

There is no fixed regimen for the management of frozen shoulder. Various treatment modalities with variable results are available including conservative treatment with physiotherapy, exercises, NSAIDs and opioid drugs, intra-articular steroids and hyaluronic acid injection, suprascapular nerve block and manipulation under anaesthesia (MUA), open arthroscopic release with or without MUA. In present study we used MUA and intra-articular steroid injection for management of frozen shoulder and assessed the results by measuring improvement in VAS score and PROM.

The present study included 30 patients with $18(60 \%)$ female and $12(40 \%)$ male patients. The mean age of the patients was 46.81 years. Non-dominating hand was involved in $76.66 \%$ of the cases. The results were in favor of similar studies done in the past $[15,16]$

B J Van Royen and P W Pavlov conducted a study on 22 patients of frozen shoulder to assess the results of treatment by distension and manipulation under local anaesthesia. In their study, 15 cases $(68 \%)$ were female and 7 cases $(32 \%)$ were male, mean age of the patients was 48 years and non-dominating hand was involved in $55 \%$ of cases [15]. Similar study conducted by $\mathrm{T}$ A Hamdan and K A AL Essa on 100 patients of frozen shoulder to compare the treatment results of saline versus steroid injection has similar observations about age of presentation, sex involved and affected limb [16]. In present study, VAS score as well as PROM were significantly improved 3 months after the treatment of frozen shoulder with manipulation under anaesthesia along with intracapsular steroid injection. The VAS score before starting the treatment was $8.1 \pm 1.2$ which was reduced to $4.3 \pm 1.0$ when measured 3 months after the treatment. Also, the degree of range of motion was improved very much in all the movement viz flexion, abduction, external rotation and internal rotation (table 1). So this treatment modality can be used as a safe and effective method to reduce pain and stiffness in frozen shoulder.

Many studies have been done in the past to assess the role of MUA in management of frozen shoulder and suggested that MUA is very effective in treatment of frozen shoulder that were not responsive to conventional treatment [9-13].

Dodenhoff $\mathrm{R}$ et al carried out a study to assess the role of MUA for the management of primary frozen shoulder and found that after 3 months follow up, $59 \%$ (29 shoulders) were rated as having no or mild disability, $28.2 \%$ (11 shoulders) as having moderate degree of disability and $12.8 \%$ (5 shoulders) were having severe degree of disability. They recommended the use of MUA in primary frozen shoulder for early recovery [9]. Hill $\mathrm{J}$ et al also studied the role of MUA for the management of frozen shoulder and concluded that manipulation allowed the patients under study to return to their normal lifestyle much sooner than the 
reported natural history of this condition would indicate. In their retrospective study, they found that out of 17 shoulders in 15 patients who were not able to perform their daily work because of their shoulder problem, 70\% of them returned to their normal work within an average period of 2.6 months after MUA [10].

A similar study was done by Kivimaki J et al in 2001 to assess the effect of MUA with and without steroid injection and concluded that MUA is an effective method to manage symptoms in frozen shoulder and use of intra-articular steroid injection did not enhance the effect of manipulation [12].

Similarly, many studies have been done in the past to assess the role of intra-articular injection of corticosteroid for idiopathic frozen shoulder with or without physiotherapy, and all studies suggested that intra-articular steroid injection is an effective method to treat symptoms in frozen shoulder [17-23]. Ahmad I et al carried out a study to assess the role of intra-articular steroid in frozen shoulder.

They injected the patients with $80 \mathrm{mg}$ of methylprednisolone and advised them to continue active ROM exercises. The patients were followed up at six weeks and twelve weeks and results were assessed and compared in terms of VAS score and ROM.

The average VAS score was 7.5 at the beginning of treatment which was improved to 3 at the end of follow up. The range of motion was also improved; abduction from $60^{\circ}$ to $95^{\circ}$ (average gain $35^{\circ}$ ) and internal rotation from $20^{\circ}$ to $40^{\circ}$ (average gain $20^{\circ}$ ) [17].

Jacobs LG et al studied to compare MUA and intraarticular steroid in management of frozen shoulder and found that both are effective in the management of frozen shoulder [24].

The present study concluded that combination of MUA and intra-articular steroid can be used for the management of frozen shoulder with very good results in terms of improved pain score and range of motion.

\section{Conclusion}

Manipulation under anaesthesia is an effective method to manage the symptoms of idiopathic adhesive capsulitis of shoulder joint (frozen shoulder) especially in the cases where conservative management has been failed to resolve the symptoms. The use of intracapsular corticosteroid injection can further enhance the effect of MUA by decreasing inflammation and fibrosis.

\section{Original Research Article}

Lastly, we suggest further studies with larger number of patients and more management methods to compare so as to achieve improvement the diagnosis and management of frozen shoulder.

\section{What this study adds to existing knowledge?}

Till now, so many treatment modalities had been tried for the management of frozen shoulder around the world. This include conservative management with physiotherapy and exercises, NSAIDs and opioid analgesics, intra-articular steroid and/ or hyaluronic acid injections, supraclavicular nerve block, manipulation under anaesthesia (MUA) and open arthroscopic release with or without MUA. Different institute have different regimen for its management with variable results. In present study, we used a combined therapy of intraarticular steroid injection with MUA for the management of frozen shoulder and we got very good results with this. We did not found any literature about the use of this combined therapy in the past and after the results of this study, we can say that this is a good alternative for the management of frozen shoulder. Further studies with larger number of study population are desirable.

Conflict of interest: No potential conflict of interest exists. No financial relationship exists between authors and products or procedures related to this article.

Author contribution: Dr. Rakesh Kumar Misra: Study concept and design, Dr. Ashish Batra: Analysis and interpretation of data, Dr. Hemant Khajja, Dr. Kunal Raja: Drafting of manuscript, Dr. Rakesh Kumar Misra: Revision and finalize the study.

Conflict of interest: None declared. Funding: Nil, Permission from IRB: Yes

\section{References}

1. Lubiecki M, Carr A. Frozen shoulder: past, present, and future. J Orthop Surg (Hong Kong). 2007 Apr;15 (1): 1-3. DOI:10.1177/230949900701500101

2. Grey RG. The natural history of "idiopathic" frozen shoulder. J Bone Joint Surg Am. 1978 Jun;60(4):564.

3. Reeves B. The natural history of the frozen shoulder syndrome. Scand J Rheumatol. 1975; 4(4):193-6.

4. Redler LH, Dennis ER. Treatment of Adhesive Capsulitis of the Shoulder. J Am Acad Orthop Surg. 2019 Jun 15; 27(12):e544-e554. doi: 10.5435/ JAAOSD-17-00606. 


\section{Original Research Article}

5. Itoi E, Arce G, Bain GI, et al. Shoulder Stiffness: Current Concepts and Concerns. Arthroscopy. 2016 Jul; 32(7):1402-14. doi: 10.1016/j.arthro.2016.03.024. Epub 2016 May 12.

6. Bunker TD, Anthony PP. The pathology of frozen shoulder. A Dupuytren-like disease. J Bone Joint Surg Br. 1995 Sep;77(5):677-83.

7. Neviaser AS, Neviaser RJ. Adhesive capsulitis of the shoulder.J Am AcadOrthop Surg.2011Sep;19(9):536-42

8. Georgiannos D, Markopoulos G, Devetzi E, et al. Adhesive Capsulitis of the Shoulder. Is there Consensus Regarding the Treatment? A Comprehensive Review. Open Orthop J. 2017 Feb 28;11:65-76. doi: 10.2174/ 1874325001711010065 . eCollection 2017.

9. Dodenhoff RM, Levy O, Wilson A, et al. Manipulation under anesthesia for primary frozen shoulder: effect on early recovery and return to activity. J Shoulder Elbow Surg. 2000 Jan-Feb;9(1):23-6.

10. Hill JJ Jr, Bogumill H. Manipulation in the treatment of frozen shoulder. Orthopedics. 1988 Sep; 11 (9): 1255-60.

11. Janda DH, Hawkins RJ. Shoulder manipulation in patients with adhesive capsulitis and diabetes mellitus: A clinical note. J Shoulder Elbow Surg. 1993 Jan; 2(1): 36-8. doi: 10.1016/S1058-2746(09)80135-3. Epub 2009 Feb 19.

12. Kivimäki J, Pohjolainen T. Manipulation under anesthesia for frozen shoulder with and without steroid injection. Arch Phys Med Rehabil. 2001 Sep;82 (9): 1188-90.

13.OthmanA, Taylor G. Manipulation under anaesthesia for frozen shoulder. Int Orthop. 2002;26(5): 268-70. Epub 2002 Mar 27. DOI:10.1007/s00264-002-0348-2

14. Hartrick CT, Kovan JP, Shapiro S. The numeric rating scale for clinical pain measurement: a ratio measure? Pain Pract. 2003 Dec;3(4):310-6. DOI:10. 1111/j. 1530-7085.2003.03034.x

15. van Royen BJ, Pavlov PW. Treatment of frozen shoulder by distension and manipulation under local anaesthesia.Int Orthop. 1996;20(4):207-10.DOI:10.1007 / s002640050064
16.Hamdan TA, Al-Essa KA. Manipulation under anaesthesia for the treatment of frozen shoulder. Int Orthop. 2003;27(2):107-9. Epub 2002 Sep 13. DOI:10. 1007/ s00264-002-0397-6

17. Ahmad I, Askar Z, Durrani Z, et al. Intraarticular injection of methylprednisolone for idiopathic frozen shoulder. J Med Sci. 2009; 17(1):16-18.

18. Arslan S, Celiker R. Comparison of the efficacy of local corticosteroid injection and physical therapy for the treatment of adhesive capsulitis. Rheumatol Int. 2001 Sep; 21(1):20-3.

19. Carette S, Moffet H, Tardif J, et al. Intraarticular corticosteroids, supervised physiotherapy, or a combination of the two in the treatment of adhesive capsulitis of the shoulder: a placebo-controlled trial. Arthritis Rheum. 2003 Mar;48(3):829-38. DOI:10. 1002 / art. 10954

20. Ryans I, Montgomery A, Galway R, et al. A randomized controlled trial of intra-articular triamcinolone and/or physiotherapy in shoulder capsulitis. Rheumatology (Oxford). 2005 Apr;44(4): 529-35. Epub 2005 Jan 18. DOI:10.1093/rheumatology/ keh535

21. de Jong BA, Dahmen R, Hogeweg JA, et al. Intraarticular triamcinolone acetonide injection in patients with capsulitis of the shoulder: a comparative study of two dose regimens. Clin Rehabil. 1998 Jun;12(3):211-5.

22. Rizk TE, Pinals RS, Talaiver AS. Corticosteroid injections in adhesive capsulitis: investigation of their value and site. Arch Phys Med Rehabil. 1991 Jan;72(1): 20-2.

23. Lee HJ, Lim KB, Kim DY, et al. Randomized controlled trial for efficacy of intra-articular injection for adhesive capsulitis: ultrasonography-guided versus blind technique. Arch Phys Med Rehabil. 2009 Dec;90 (12): 1997-2002. doi: 10.1016/j.apmr.2009.07.025.

24. Jacobs LG, Smith MG, Khan SA, et al.Manipulation or intra-articular steroids in the management of adhesive capsulitis of the shoulder? A prospective randomized trial. J Shoulder Elbow Surg. 2009 MayJun; 18(3):348-53. doi: 10.1016/j.jse.2009. 02.002.

\section{How to cite this article?}

Misra R.K., Batra A., Khajja H., Raja K. Manipulation under anaesthesia with local intracapsular steroid injection in treatment of frozen shoulder. Surgical Update:Int J surg Orthopedics.2019;5(2):116-120.doi:10.17511/ijoso.2019.i02.09. 